\title{
Study on Silting Characteristics of the Trial Dredged-Trough for Immersed Tube Tunnel
}

\author{
Jie $\mathrm{He}^{1,2, \mathrm{a}}$, Xinsheng Zhao ${ }^{3, \mathrm{c}}$ \\ ${ }^{1}$ Nanjing Hydraulic Research Institute, Nanjing, China \\ ${ }^{2}$ State Key Laboratory of Hydrology-Water Resource and Hydraulic Engineering, Nanjing, China \\ ${ }^{3}$ Hydrology Bureau of Yellow River Conservancy Commission, Zhengzhou, China \\ ajhe@nhri.cn, byrcczxs@163.com
}

Keywords: Trial Dredged-Trough, Sediment Observation, Slope, Fluid Mud.

Abstract. On the basis of studying water-sediment movement in the Lingdingyang sea area, sedimentation characteristics of the trial dredged-trough of immersed tube tunnel of HZMB are analyzed, with 17 groups of underwater topographic survey data and the measured results of fluid mud and silt unit weight in the base trough and slopes. And some results are obtained, including siltation rate changes and its distribution characteristics of the trial dredged-trough, the slope ratio of steady slope, the thickness and its trends of the fluid mud layer and silt layer in the trough. This paper analyzes the different impacts of flood and typhoon on sedimentation, and points out that the first flood from dry season in flood season will increase siltation clearly.

\section{Introduction}

A planned Hong Kong-Zhuhai-Macao Bridge (HZMB), from west Zhuhai Macao to east Hong Kong, crosses the Lingdingyang baymouth of the Pearl River estuary which is the most important waterway along it many large vessels must pass through from Guangzhou, Shenzhen harbors in the South China. In order to meet navigation requirements, a design scheme of a bridge in combination with tunnel has been worked out, i.e. the seabed tunnel structure is placed on the Lingdingyang main navigable section by use of the immersed tube tunnel construction. Because Dahao waterway through which the tunnel passes has a deep waterway with high velocity, a base trough $5400 \mathrm{~m}$ in length and $42 \mathrm{~m}$ in depth must be excavated if the immersed tube tunnel is used. However, a few issues such as excavation of the base trough, sedimentation after excavation, density distribution and slope stability have aroused considerable attention.

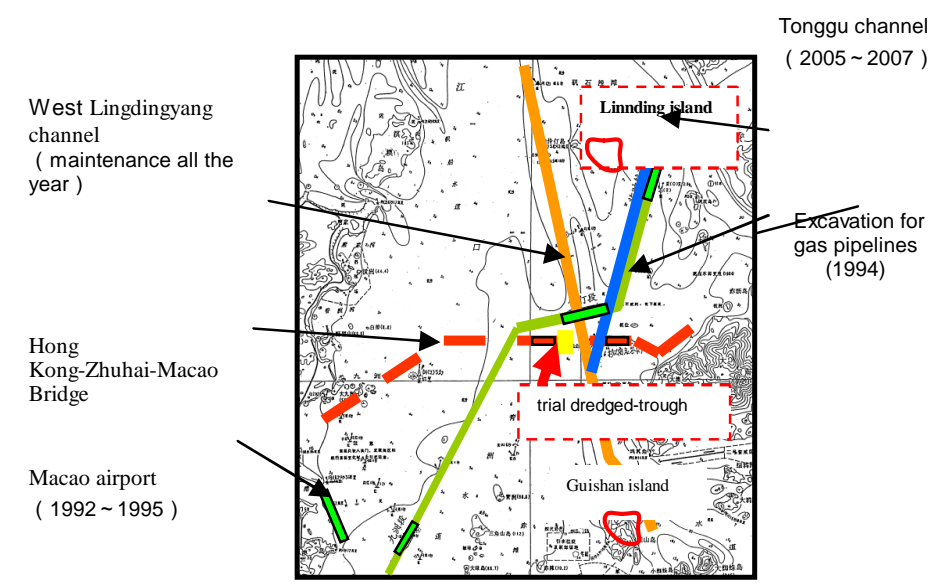

Figure 1 Sketch Of The Trial Dredged-trough

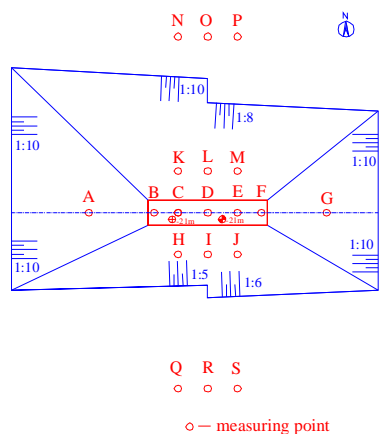

Figure 2 Layout Of the Trial Dreged-Trough and the Observation Points

In order to understand these questions, a sedimentation observation of the trial dredged-trough and its analysis should be carried out in the study. The trial dredged-trough is choosen in the east sea-bed of the west artificial Island, which has a length of $100 \mathrm{~m}$ and $-21 \mathrm{~m}$ in bottom elevation (average depth of excavation $11.5 \mathrm{~m}$ ), from east to west, and respectively having the slope ratio of 1:5,1:6 (south side) 
and 1:8,1:10 (north side). And its location is shown in fig. 1 and its excavation scale is shown in fig. 2. Construction excavation and topographic survey after excavation have been completed by Guangzhou Navigation Bureau Corp. Ltd, and Nanjing Hydraulic Research Institute carried on researches such as sediment bulk density observation and sedimentation analysis.

\section{Field Observation of the Trial of the Dredged-Trough}

\section{Observation Time Period}

The trial dredged-trough was completed on February 6, 2009, and observation period starts from that date until October 14, lasted a total of 250 days, which spans more than eight months, i.e. spring, summer and autumn, during which suffered from a relatively large flood and two typhoons.

Observation Records

(1) Underwater topography survey for slope and the base trough of the trial dredged-trough was done for 17 times using the multi-beam and dual-frequency sounder.

(2) Fluid mud and sludge bulk density detection for slope and the base trough of the trial dredged-trough was done for 4 times using $\gamma$-ray sludge densitometer.

(3) Sea-bed material sampling and particle analysis were done for many times on the seabed excavated as the base trough of the trial dredged-trough and its slope.

The field observation and periods corresponding to items above are listed in table 1.

Tab. 1 The Field Observation Items Of The Trial Dredged-trough and Corresponding Statistical Times

\begin{tabular}{|c|c|c|c|c|c|}
\hline No & $\begin{array}{c}\text { Observation } \\
\text { Time }\end{array}$ & Regime & $\begin{array}{l}\text { Topographic } \\
\text { Survey }\end{array}$ & $\begin{array}{l}\text { Bulk Density } \\
\text { Observation }\end{array}$ & $\begin{array}{l}\text { Bed Material } \\
\text { Sampling }\end{array}$ \\
\hline 1 & 2009.02 .06 & \multirow{9}{*}{$\begin{array}{l}\text { Before } \\
\text { flood }\end{array}$} & $\sqrt{ }$ & $\sqrt{ }$ & $\sqrt{ }$ \\
\hline 2 & 2009.02 .15 & & $\sqrt{ }$ & & \\
\hline 3 & 2009.02 .23 & & $\sqrt{ }$ & & \\
\hline 4 & 2009.03 .02 & & $\sqrt{ }$ & & \\
\hline 5 & 2009.03 .10 & & $\sqrt{ }$ & & \\
\hline 6 & 2009.03.26 & & $\sqrt{ }$ & & \\
\hline 7 & 2009.03 .31 & & $\sqrt{ }$ & & \\
\hline 8 & 2009.04 .11 & & $\sqrt{ }$ & $\sqrt{ }$ & $\sqrt{ }$ \\
\hline 9 & 2009.05 .08 & & $\sqrt{ }$ & & \\
\hline 10 & 2009.05 .27 & \multirow{6}{*}{$\begin{array}{l}\text { During } \\
\text { flood }\end{array}$} & $\sqrt{ }$ & & \\
\hline 11 & 2009.06 .13 & & $\sqrt{ }$ & & \\
\hline 12 & 2009.07 .09 & & $\sqrt{ }$ & $\sqrt{ }$ & $\sqrt{ }$ \\
\hline 13 & 2009.07 .24 & & $\sqrt{ }$ & & \\
\hline 14 & 2009.08 .08 & & $\sqrt{ }$ & & \\
\hline 15 & 2009.09 .09 & & $\sqrt{ }$ & & \\
\hline 16 & 2009.09 .24 & \multirow{2}{*}{$\begin{array}{l}\text { After } \\
\text { flood }\end{array}$} & $\sqrt{ }$ & & \\
\hline 17 & 2009.10 .13 & & $\sqrt{ }$ & $\sqrt{ }$ & $\sqrt{ }$ \\
\hline
\end{tabular}

\section{Change in plane topography}

it is shown in Fig. 3 that eight contour maps of the trial dredged-trough, the order is from early February 2009 to middle period of September which is one piece month by month. From changes in contour distribution it can be seen that the overall base trough of the trial dredged-trough was covered by $-21 \mathrm{~m}$ contour , and $-21.5 \mathrm{~m}$ contour range accounted for $60 \%$ of the base trough (fig.3.a) ; Since then, the water depth in the trough was gradually becoming shallow and $-21 \mathrm{~m}$ contour range accounted for $70 \%$ of the base trough, and the rest of region is referred to $-20.5 \mathrm{~m}$ water depth to the third month 
(fig. 3.d).These three months belongs to the dry season and the trial dredged-trough in general tends to be shallow, but its amplitude is not great.

The flood season is coming after May, siltation in the trial dredged-trough has been gradually becoming significant (see fig. 3.e 5.g), and in it the $-21 \mathrm{~m}$ contour almost completely disappeared, and the $-20.5 \mathrm{~m}$ contour range also showed a marked tendency to reduction after three months ( June, July and August ) . Fig. 5h shows contours of the trial dredged-trough in September. And some changes in the topography in the trough at this time had been from fast to slow, comparing with that in August (fig. 3.g), and the $-20.5 \mathrm{~m}$ contour range had slightly expanded, and it is shown that the impacts of the flood season on sedimentation in the trial dredged-trough have been gradually becoming weak.

From changes in contour distribution during various periods it can also be found that siltation in the eastern base trough is shallower than that in the western, but the siltation distribution is still relatively gentle. From particle analysis of sampling of the bed-load it is found that the median size of silt is about $0.008 \mathrm{~mm}$, and from these above it can be seen that the main silt in the trial dredged-trough is composed mainly of fine-grained suspended sediment.

It can be seen from comparison between the contours of each month that the slope is not very smooth when the trial dredged-trough formed and the contour distribution is also uneven. After scouring and silting for a few months, on both the east-western longitudinal and the south-northern horizontal slopes the contour distributions come and go with regularity and the trial dredged-trough slopes have shown a stable tendency.

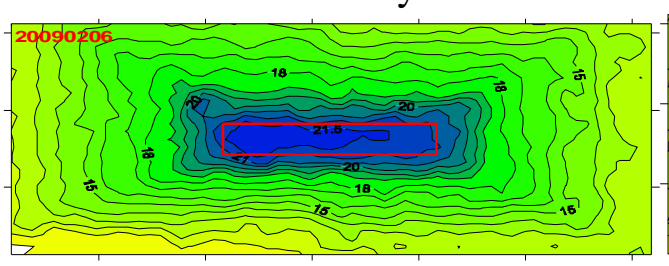

a. ( 2009.02.06)

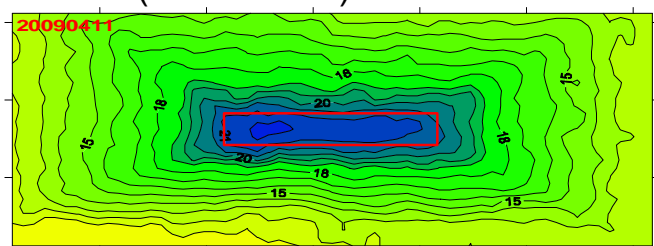

c. ( 2009.04.11)

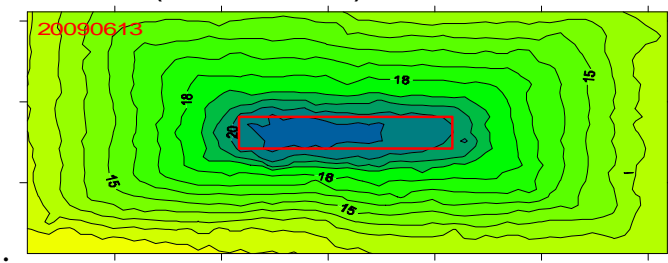

e. $(2009.06 .13)$

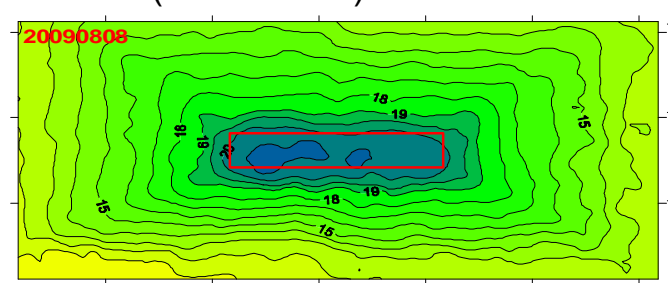

g. ( 2009.08.09)

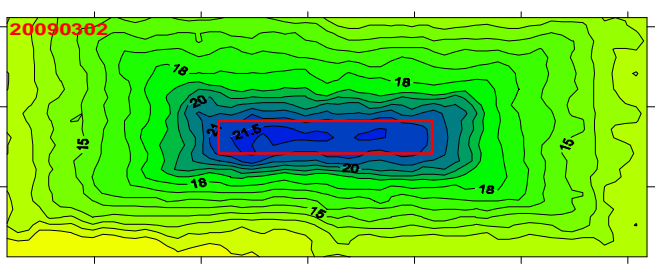

b. ( 2009.03.02)

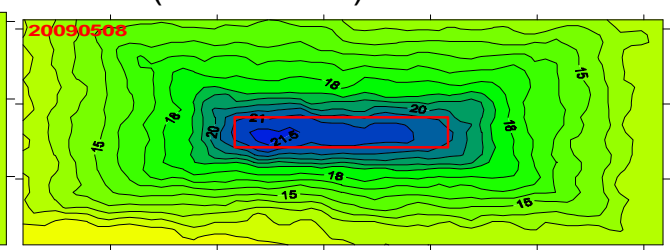

d. ( 2009.05.08)

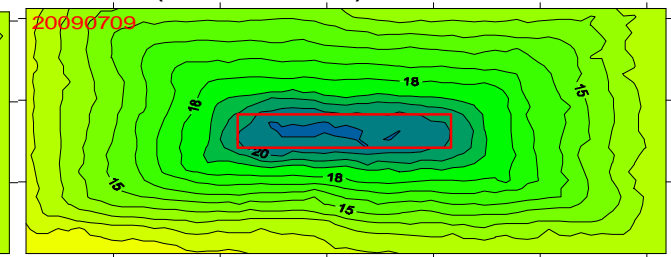

f. ( 2009.07.09)

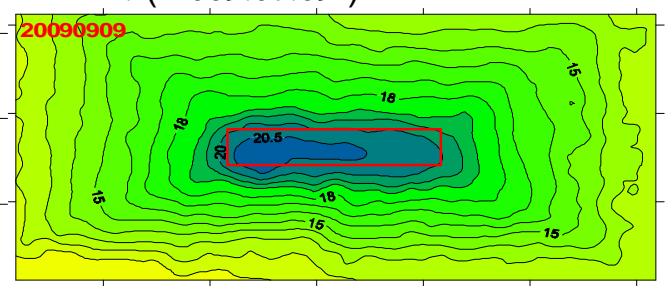

h. ( 2009.09.09)

Figure.3 Monthly Changes In Contour Distributions Of The Trial Dredged-trough 


\section{Conclusions}

(1) The depth data obtained from 17 measuring times indicate that the mean siltation in the trail dredged-trough is up to $1.23 \mathrm{~m}$ during more than eight months, of which the siltation during the low water period of 3 months is up to $0.40 \mathrm{~m}$, and the siltation during the flood period of 4 months is up to $0.74 \mathrm{~m}$, and the siltation during the post-flood of more than one month is up to $0.09 \mathrm{~m}$. The intensity of sedimentation in the trial dredged-trough during flood period is relatively great.

(2) From analysis of hydrometeorological data in the observation period it is found that most remarkable sedimentation in the trail dredged-trough didn't occur in the initial period when the trough forming or in a typhoon period, and that occurred after the first flood. After then there is no significant effect on sedimentation in the trail dredged-trough, whatever a flood may be great. This feature gave us a new basis for futher research of sedimentation in harbors and waterways in the Lingdingyang sea area in the tail end of spring and in early summer.

\section{References}

[1] Xu Jun-liang et al.(1993) .Evolution and Development of the Pearl River Delta Waterways with Ports and Rational Harbor Layout . China Ocean Press, 1993(3),pp12-18.

[2] Chen Yao-tai et al. (1992).Modern sedimentary velocity and sedimentary environment in the Pearl River mouth.Journal of Zhongshan University (Natural Science), Volume Two,Issue 31.

[3] Li Chun-chu, Lei Ya-ping, He Wei et al. (2002).Evolutional processes of the Pearl River estuary and its protective regulation and exploitation.Journal of Sediment Research, pp44-51

[4] Chen Zhi-min, Cai Nan-shu, Xin Wen-jie.(2002).Analysis on the sedimentation of the Lingdingyang channel in the Zhujiang estuary. The Ocean Engineering, Volume Twenty, Issue 3. 